\title{
Retrieval processes that produce interference in modified forced-choice recognition tests
}

\author{
CARLA C. CHANDLER \\ Washington State University, Pullman, Washington \\ and \\ GARY J. GARGANO \\ Saint Joseph's University, Philadelphia, Pennsylvania
}

\begin{abstract}
Recognition can suffer if the retrieval cues activate more than one trace (e.g., for Flower A and Flower $A^{\prime}$ ). We found evidence for two retrieval processes by examining interference effects in forcedchoice tests (e.g., Did you see Flower A or Flower A"?). Experiment 1 provided evidence of a problem in discriminating between temporally and contextually similar traces that were formed in the study phase. A competitor (Flower $A^{\prime}$ ) interfered more if it was shown in the study phase rather than in the test phase. Experiments 2 and 3 found evidence for a blocking process in recognizing pairs of words (child-apple). A competitor interfered more if it was recent, shown at test rather than at study. This pattern occurred regardless of whether the competitor was similar to the target (child-orange) or dissimilar to it (child-truck). The importance of a particular retrieval process may depend on an item's representation as well as on the retrieval cues.
\end{abstract}

A long-standing question in memory research is what retrieval processes are important for recognizing verbal events (e.g., names, sentences, paragraphs, and new jargon) and nonverbal events (e.g., novel faces and landscapes). While retrieval processes were originally developed to explain effects found in recall, such processes may affect recognition. The purpose of this study was to examine retrieval processes in recognition and to determine whether the same processes were involved in recognizing different kinds of materials (e.g., nature pictures and sentences).

Although retrieval problems have often been considered for recall, they have been considered less often for recognition memory. Most studies that have examined retrieval problems in recognition have attributed them to a mismatch between the retrieval cue and the memory trace. It is widely acknowledged that a target word is recognized more often if a contextual word is reinstated than if it is not (e.g., Light \& Carter-Sobell, 1970; Thomson, 1972; Tulving \& Thomson, 1971). For example, Tulving and Thomson (1971) presented pairs of words (e.g., artgirl) and asked the subjects to think about how the words

Portions of this article were presented at the 1993 meeting of the Psychonomic Society in Washington, DC, and at the 1993 meeting of the American Psychological Association in Chicago. We thank Marcey Brown, Jenny Brunz, Bunpa Lim, Brian Holt, Andrea Seeley, Kevin White, and Jack Yearout for their help in testing the subjects. Address any correspondence concerning the article to $\mathrm{C}$. $\mathrm{C}$. Chandler, Department of Psychology, Washington State University, Pullman, WA 99164-4820 (e-mail: chandler@wsunix.wsu.edu).

-Accepted by previous editor, Geoffrey R. Loftus were related. On a recognition test, a target (e.g., girl) was recognized more often if the contextual word was reinstated (art-girl) than if the contextual word was deleted ( irl) or changed (adult-girl).

Similarly, recognition of unfamiliar faces has been found to be more accurate if the original environment is reinstated than if it is not. Environmental context effects have been found in yes/no recognition tests (e.g., Cann \& Ross, 1989; Dalton, 1993; Shapiro \& Penrod, 1986) and in line-up identification tests (e.g., Cutler, Penrod, \& Martens, 1987; Gibling \& Davies, 1988; Krafka \& Penrod, 1985). Environmental context effects are consistent with the view that recognition is less likely if the retrieval cue does not match the trace.

The purpose of the present study was to examine the possibility that additional retrieval processes could lead to problems in recognition tests. The need to consider additional retrieval processes is illustrated by some studies reported by Chandler $(1989,1991)$. Targets (e.g., Flower A) were shown, and the subjects were tested using a forcedchoice test (e.g., Did you see Flower A or Flower $A^{\prime \prime}$ ?). Recognition was lower if a Flower $A^{\prime}$ was shown after the target (experimental condition) than if it was not (control condition) - an interference effect. Because the retrieval cue (Flower A vs. Flower A") matched the target trace (Flower A), some process other than encoding specificity must be producing the interference effect. ${ }^{1}$

Chandler (1991) considered the possibility that Flower A' altered the trace for Flower A (e.g., Belli, Windschitl, McCarthy, \& Winfrey, 1992; Loftus, 1979), but concluded that a retrieval process was involved instead. If trace alteration caused the interference effect, then the effect should be permanent. The interference effect should have 
remained (or increased) across a retention interval, but it did not. Instead, Flower $A^{\prime}$ no longer interfered at a 2-day retention interval, and performance improved in the experimental condition (see Windschitl, 1996, for a similar result using human faces and various instructions). Instead of altering the memory trace for Flower A, Flower $A^{\prime}$ must have interfered with its retrieval at the 15 -min retention interval. ${ }^{2}$

Two retrieval processes, a discrimination process and a blocking process, might explain the interference effects found in Chandler's $(1989,1991)$ experiments. Both retrieval processes are assumed to occur only if (a) the retrieval cue matches more than one memory trace, and (b) the trace for Flower $A^{\prime}$ is activated. Performance should be higher if the cue matches only the target trace (control condition) than if the cue matches an additional trace (experimental condition). Furthermore, Flower $\mathrm{A}^{\prime}$ should interfere only if it is activated during the test. We used a short retention interval and test cues that would activate the competitor. Our goal was to determine whether discrimination and blocking processes caused interference in forced-choice recognition tests. Each process is described next, followed by a description of its predictions.

According to feature recombination models of memory, a retrieval problem arises if features from two traces are activated simultaneously. Once these features are activated, they may recombine, and the recombined set of features will not match the target. For example, the eyes from one face may be recombined with the hair from another face (e.g., Metcalfe, 1990; Reinitz, Lammers, \& Cochran, 1992; Reinitz, Morrisey, \& Demb, 1994). In agreement with the idea, Reinitz et al. (1992) found that subjects often claimed to recognize a face that was constructed from the features of two old faces.

If features recombine in a retrieval buffer, then it may be difficult to tell which features occurred together. In other words, it may be difficult to determine which features co-occurred as Flower $\mathrm{A}$ and which features cooccurred as Flower $A^{\prime}$. This idea, which we will call a discrimination process, has not been given a role in modern models of memory (e.g., Reinitz et al., 1992), although it played a role in early theories. For example, Postman (1963, p. 42) talked about the need to discriminate between two responses, and Underwood $(1969$, p. 569) talked about the need to discriminate between traces.

A discrimination process may have caused the interference effects found in Chandler's (1991) studies with the nature pictures. The test cues activated the trace for the target and for the competitor, and the features recombined. Because both traces were formed in the study phase, they shared contextual features as well as perceptual features. Consequently, the subjects could not tell which features comprised the target. Recognition performance suffered as compared with a control condition in which only the target was shown.

Thus, failing to discriminate between traces could cause interference effects. If so, then interference effects should be larger if the traces shared contextual features than if they did not. Interference effects should be large if Flower $A$ and Flower $A^{\prime}$ were shown in the study phase. The interference effect should be smaller if Flower $A$ was shown at study while Flower $A^{\prime}$ was shown at test. Because the traces possess different contextual features, it should be easy to tell which features occurred together. Thus, Flower $A^{\prime}$ should interfere more if it was shown at study than if it was shown at test. We tested this prediction using nature pictures in Experiment 1 and pairs of words (e.g., child-apple) in Experiments 2 and 3.

We did not expect to find the same pattern of results with the word pairs, because the discrimination process should be trivial for these materials. If the test cues activated features of both apple and orange, it would be easy to tell which features were part of the apple versus the orange. Knowledge of apples tells one which features must be part of the apple.

Another retrieval process that may lead to problems in recognition is a blocking process. Originally, a blocking process was proposed by Rundus (1973) to explain effects found in recall. According to his model, an organizing idea (e.g., fruit) is associated with the target apple and with competing items (e.g., orange). Strengthening the association between fruit and orange lessens the chance of sampling the target apple. In models of a blocking process, the competitor either robs activation from the target or is sampled in place of the target (see Anderson \& Bjork, 1994, for a review; Bjork \& Bjork, 1988; Roediger, 1973, 1978; Rundus, 1973). Although a blocking process was proposed to account for retrieval problems in recall, it may explain retrieval problems in recognition tests. We assume that recent competitors will be most strongly associated with the cue. These strong items are most likely to be resampled and to interfere with recognition of the target. Thus, a competitor presented during the test should interfere more than a competitor presented during the study phase.

Both of the proposed retrieval processes contend that the amount of interference depends on whether the competitor is shown at study or at test (see also Chandler \& Gargano, 1995). However, they make opposite predictions. A discrimination process predicts more interference if Flower $\mathrm{A}^{\prime}$ is shown at study, whereas a blocking process predicts more interference if Flower $A^{\prime}$ is shown at test. The opposing predictions allow us to tell which retrieval process is important in recognizing nature pictures and which process is important in recognizing word pairs.

\section{EXPERIMENTS 1A-1C}

Experiments $1 \mathrm{~A}, 1 \mathrm{~B}$, and $1 \mathrm{C}$ represent three replications of the same experiment. In each experiment, nature pictures (e.g., Flower A) were shown and tested using a modified recognition test (Did you see Flower A or Flower $A^{\prime \prime}$ ?). We manipulated whether Flower $A^{\prime}$ was never presented (control), shown twice during the study phase (at study), or shown once during the test (at test). 
In Experiment 1A, every subject participated in each of the three conditions. In Experiments $1 \mathrm{~B}$ and 1C, every subject participated in the control condition and in one of the other conditions. For ease of exposition, the method and results will be described for each experiment, followed by a discussion.

\section{Experiment 1A}

\section{Method}

Subjects and Design. Undergraduates at Washington State University $(N=36)$ participated as subjects in order to fulfill a requirement for their introductory psychology class.

Every subject participated in three conditions containing 24 target pictures (e.g., Flower A) each. The conditions were defined by when a related picture (e.g., Flower $A^{\prime}$ ) was presented: during the study phase (at-study condition), during the test phase (at-test condition), or never presented (control condition).

Materials. The materials were 72 nature scenes that had been divided into three pictures of equal size (see Figure 1 and Chandler, 1989, for examples). Each picture was mounted on a $5 \times 7$ in. card. Each picture served as a target $(A)$, a related picture $\left(A^{\prime}\right)$, and a distractor on the recognition test ( $\left.\mathrm{A}^{\prime \prime}\right)$ equally often in the experiment.
Procedure. The 72 targets were shown sequentially by flipping through a stack of $5 \times 7$ in. cards at a $10-\mathrm{sec}$ rate. As an orienting task, the subjects rated each picture on a scale from $1=$ simple to $5=$ complex. They assigned two numbers to each picture to indicate their first and second impressions of the picture's complexity. Immediately afterward, another 24 pictures were shown at a 10 sec rate. Each of the pictures was related to one of the targets in the at-study condition. The subjects rated each picture on a scale from 1 = unpleasant to $5=$ pleasant, indicating their first and second impressions of the picture's pleasantness. Then the same 24 pictures were presented again and, once again, were rated for pleasantness.

The subjects then chatted with the experimenter for a few minutes before taking the forced-choice recognition test. The test occurred $15 \mathrm{~min}$ after the last target picture was shown.

In the forced-choice test, the target (Flower A) was shown beside a novel picture (Flower $A^{\prime \prime}$ ) of the scene. The experimenter emphasized that only one of the pictures had been shown previously and asked the subjects to choose that picture. The targets appeared on the left- and right-hand sides equally often on the test.

To create the at-test condition, a rating task was interwoven with the recognition test. In the at-test condition, the subjects rated the nontarget's pleasantness (Flower $A^{\prime}$ ) just before seeing the test alternatives (Flower A vs. Flower $A^{\prime \prime}$ ). This occurred 24
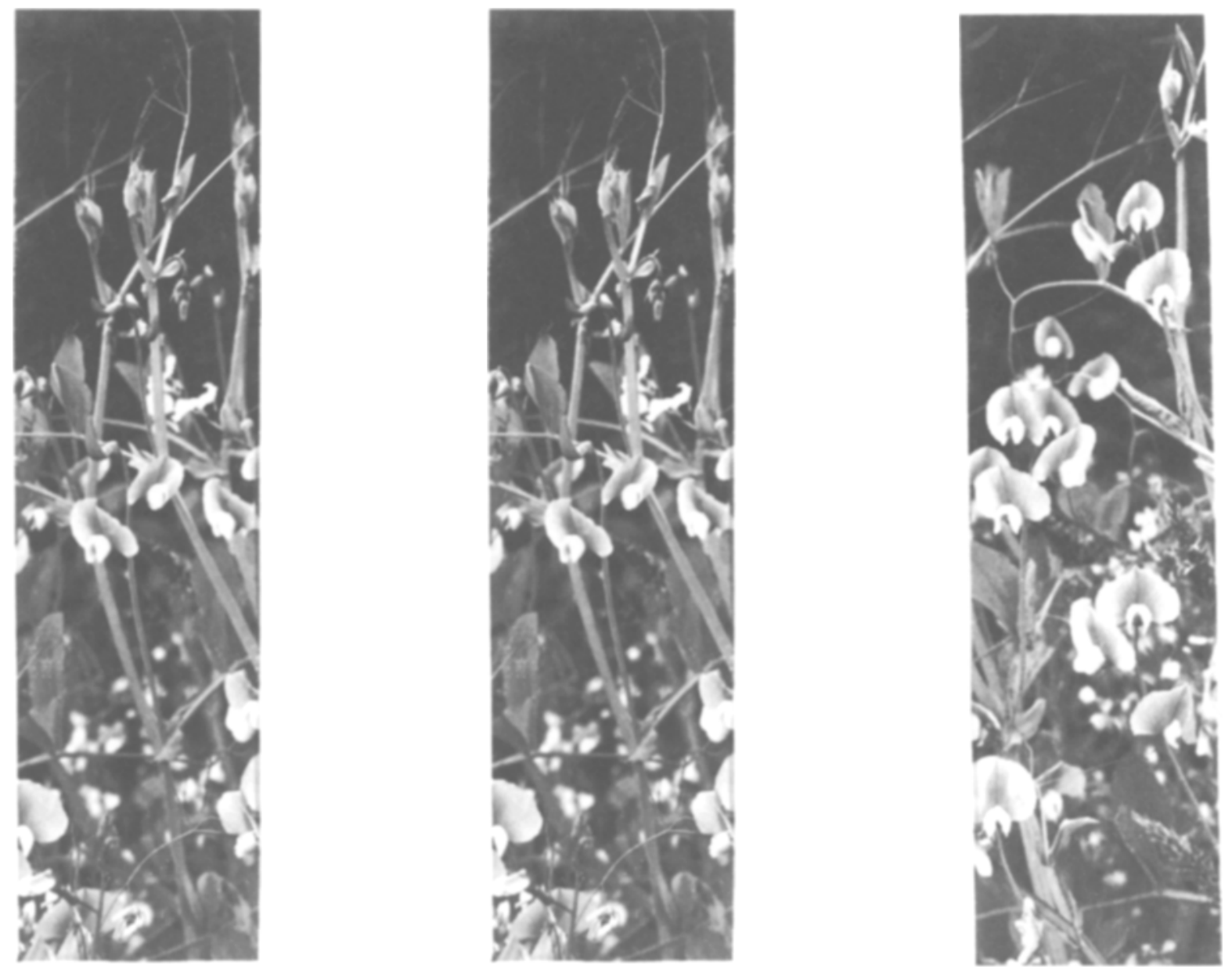

Figure 1. Flower $A$, Flower $A^{\prime}$, and Flower $A^{\prime \prime}$ are examples of the nature picture materials used in Experiments 1A, 1B, and 1C. Each picture served as the target, nontarget, and novel test item equally often across subjects. 
Table 1

Mean Percentage of Targets (Flower A) Correctly Recognized and Confidence Intervals for Interference Effects

\begin{tabular}{lllllll}
\hline \multicolumn{1}{c}{$\mathrm{A}^{\prime}$ Shown } & \multicolumn{2}{c}{ Experiment 1A } & Experiment 1B & \multicolumn{2}{l}{ Experiment 1C } \\
\hline Control & 79.6 & & $82.0^{*}$ & $79.2^{*}$ & \\
At Study & 73.3 & $( \pm 5.7) \dagger$ & 74.1 & $( \pm 3.2) \dagger$ & 70.4 & $( \pm 5.4) \dagger$ \\
At Test & 78.8 & $( \pm 4.3)$ & 81.7 & $( \pm 2.6)$ & 77.6 & $( \pm 5.9)$ \\
At Study+Test & & & 73.9 & $( \pm 3.0) \dagger$ & 71.4 & $( \pm 6.0) \dagger$ \\
\hline
\end{tabular}

Note-The standard deviations for these percentages ranged from $10 \%$ to $12 \%$ in Experiment $1 \mathrm{~A}$ and from $8 \%$ to $11 \%$ in Experiments $1 \mathrm{~B}$ and $1 \mathrm{C}$. Each number in parentheses indicates a confidence interval for an interference effect. *Performance differed by only $2 \%$ in Groups 1, 2, and 3, so the mean performance of the three groups is reported here. In the statistical comparisons, the control conditions were not combined. +Performance was significantly lower than in the control condition.

times in a test that contained 72 items. The subjects were tested in pairs, and the experimenter waited for each subject to respond before displaying the next item on the test.

\section{Results}

The percentages of correct choices in the recognition test are displayed by condition in Table 1 . Each percentage correct is based on 864 observations ( 36 subjects responding to 24 items). The target was recognized equally well in the control condition (79.6\%) and at-test conditions $(78.8 \%)$, but performance was lower in the at-study condition (73.3\%). Statistical comparisons that support these conclusions are reported below.

We made three preplanned pairwise comparisons $(j)$ between the three means $(k)$ and held the familywise error rate at $\alpha=.05$. The alpha for each comparison, using the Bonferroni-Dunn equation

$$
\left[\alpha_{P C}=\frac{(k-1) \alpha_{F W}}{j}\right],
$$

was .033 , with a critical $t=2.22$. Then, using the general formula (difference in means) $\pm[$ (critical $t)$ (standard error)], we constructed a confidence interval for each effect. The standard error was calculated using only the two conditions being compared, as Keppel (1991, p. 356) suggests. All means and standard errors are expressed as percentages correct rather than as numbers correct.

Table 1 displays the mean percent correct in the control and experimental conditions. The confidence interval for each interference effect is shown in parentheses. By definition, an interference effect is present if performance is higher in the control condition than in an experimental condition. A significant interference effect was found if $A^{\prime}$ was shown at study but not if it was shown at test.

The magnitude of the interference effect depended on when $\mathrm{A}^{\prime}$ was shown. The interference effect was larger by $5.5 \% \pm 5.2 \%$ if $\mathrm{A}^{\prime}$ was shown at study (control minus at study) rather than at test (control minus at test). Two replications of these findings are reported next, followed by a discussion of the results.

\section{Experiments 1B-1C}

\section{Method}

Subjects and Design. The number of undergraduate subjects was 144 in Experiment $1 B$ and 72 in Experiment 1C. In each experiment, the subjects were randomly assigned to three groups, which we call Group 1, Group 2, and Group 3.

In each group, every subject contributed 32 observations to the control condition described in Experiment 1A. Every subject contributed 32 observations to an experimental condition in which the target (Flower $\mathrm{A}$ ) was followed by a related picture (Flower $\mathbf{A}^{\prime}$ ). The group determined when the $A^{\prime}$ picture was shown, either twice at study (Group 1), once at test (Group 2), or twice at study and once during the test (Group 3).

Procedure. The procedure was similar to that of Experiment $1 \mathrm{~A}$. All of the subjects rated 64 targets for complexity. Items related to 32 targets were presented and rated for pleasantness in order to create the at-study condition (Group 1) and the at-studyand-test condition (Group 3 ). The experimenter chatted with the subjects long enough to create a 15 -min retention interval for everyone.

To create the at-test condition (Group 2) and the at-study-andtest condition (Group 3), some subjects rated a picture for pleasantness (Flower $A^{\prime}$ ) just before the forced-choice decision ("Did you see Flower A or Flower A"?"). This occurred 32 times in a test over 64 items. Group 3 had seen the picture in the study phase of the experiment and rated it again.

Experiments $1 \mathrm{~B}$ and $1 \mathrm{C}$ were identical except for the task that was interwoven with the test. In Experiment 1B, the subjects rated the pleasantness of the picture (Flower $A^{\prime}$ ). In Experiment $1 \mathrm{C}$, the subjects indicated whether the picture was identical or similar to a picture that they had seen earlier or was new.

\section{Results and Discussion}

The mean percentage of correct choices in the forcedchoice recognition test is displayed by group and by condition (control, experimental) in Table 1. Each mean is based on 1,536 observations in Experiment $1 \mathrm{~B}$ (48 subjects responding to 32 targets) and on 768 observations in Experiment 1C (24 subjects responding to 32 targets).

We made five preplanned pairwise comparisons in Experiments $1 \mathrm{~B}$ and 1C. In each experiment, confidence intervals were constructed for each effect using an alpha of .03 , which held the familywise error rate at .05 . The confidence intervals express a difference in the percentage of correct responses.

Table 1 shows a confidence interval for the interference effect found in each group. Compared with performance in the control condition, performance was lower if $A^{\prime}$ was shown during the study phase (at study or both at study and at test) but not if it was shown only on the test (at test).

Confidence intervals were also constructed in order to compare the amount of interference that occurred in the groups. The interference effect was larger for Group 1 (control minus at study) than for Group 2 (control minus at test). The difference in the magnitude of the interference effect was $7.7 \% \pm 3.8 \%$ in Experiment $1 \mathrm{~B}$ and $8.4 \% \pm 6.9 \%$ in Experiment $1 \mathrm{C}$.

A discrimination process can best explain why Flower $A^{\prime}$ interfered if it was shown at study but not if it was shown at test. Showing Flower $A$ and Flower $A^{\prime}$ at study created traces that were similar in perceptual, tem- 
poral, and contextual features and could not be discriminated, which resulted in large interference effects. In contrast, showing Flower $A$ at study and Flower $A^{\prime}$ at test created traces that could be discriminated by their temporal and contextual features, and interference was averted.

Some modern theories contend that features from two traces are recombined during retrieval (e.g., Metcalfe, 1990; Reinitz et al., 1992). By itself, feature recombination cannot explain why Flower $A^{\prime}$ interfered more if it was shown at study. However, if recombination accounts were to add a discrimination process, the new model could explain the findings.

No evidence for a blocking process was found in Experiment 1 . The most recent and strongest competitor, presented at test, produced no interference. Another comparison provides a further test of a blocking process. A competitor shown at study would be strengthened by re-presenting it in the test phase. These strong competitors, shown at both study and test, did not interfere more than did competitors shown only at study. The amount of interference changed by $-1.7 \% \pm 4.31 \%$ in Experiment $1 \mathrm{~B}$ and by $0 \% \pm 6.12 \%$ in Experiment $1 \mathrm{C}$.

\section{EXPERIMENTS 2A-2B}

While a discrimination problem may cause interference in recognizing nature pictures, it may not occur for more familiar materials (e.g., word pairs such as childapple). Each nature picture is an almost arbitrary collection of perceptual features in the sense that past experience does not determine which features should go together. If features from two such traces are activated, how does the subject decide which features co-occurred? Unless the traces differ in temporal or contextual cues, there would be no way to tell.

Although a word pair is represented by a collection of temporal, semantic, and perceptual attributes (e.g., Tulving \& Bower, 1974; Underwood, 1969; Wickens, 1970), the collection of features in a word can be predicted on the basis of one's knowledge. Thus, each word is likely to be remembered as a cohesive unit. The concept has been referred to as degree of codification (Salasoo, Shiffrin, \& Feustel, 1985), redintegration (Horowitz \& Prytulak, 1969), unitization (Graf \& Schacter, 1989; LaBerge \& Samuels, 1974), or chunking (Miller, 1956). Although the features from two traces (for child-apple and childorange) may be activated simultaneously, each codified trace remains distinct. Knowledge specifies that orange and soft interior are features of an orange and these features must have co-occurred. The features orange and hard interior would not combine, even though they are in the retrieval buffer at the same time. Thus, a discrimination problem would not arise with codified materials.

Although we did not expect to find a discrimination problem with these materials, we wanted to maximize the chance of finding such a problem, if it existed. We used $\mathrm{A}-\mathrm{B}$ targets (child-apple) and $\mathrm{A}-\mathrm{B}^{\prime}$ items (child- orange) that were semantically similar, and a test that contained items from the same semantic category (e.g., apple, grape, pear, banana, peach). Evidence for a discrimination process would be found if showing $A-B^{\prime}$ at study interfered more than showing $A-B^{\prime}$ at test.

Although no evidence for a blocking process was found in Experiment 1, we entertained the possibility that such a process would occur in Experiment 2. A blocking process predicts that $A-B^{\prime}$ should interfere most if it was shown recently and was strong.

\section{Method}

Subjects and Design. Each of 168 undergraduate volunteers were assigned randomly to participate in Experiment 2A or Experiment $2 \mathrm{~B}$, resulting in 84 subjects in each experiment. Experiments $2 \mathrm{~A}$ and $2 \mathrm{~B}$ differed only in their retention intervals, which were $15 \mathrm{~min}$ in Experiment 2A and $24 \mathrm{~h}$ in Experiment 2B.

In each experiment, every subject participated in four conditions. The conditions are defined by when the $A-B^{\prime}$ item was presented: once at study (study 1 ), three times at study (study3), once on the test (test1), or not at all (control). The items were counterbalanced so that each target appeared in each condition equally often across subjects.

Materials. To obtain A-B targets, A-B' nontargets, and foils that were related, we used categories from the Battig and Montague (1969) norms. Six high associates were selected from each of 24 categories (e.g., apple, banana, grape, pear, peach). By random assignment, one exemplar became the response word in the A-B target (e.g., child-apple), one exemplar became the response word in the $A-B^{\prime}$ item (e.g., child-orange), and the four remaining exemplars served as foils on the recognition test. All of the words were common English nouns 4-11 letters long.

We constructed the $24 \mathrm{~A}-\mathrm{B}$ targets by taking 24 unrelated stimulus words (obtained from Graf \& Schacter, 1987) and randomly pairing each stimulus word (e.g., child) with one of the 24 target responses (e.g., apple). For each of the A-B targets (e.g., childapple), we constructed a corresponding $\mathrm{A}-\mathrm{B}^{\prime}$ item (e.g., childorange). Each word pair had a low preexperimental association.

The study list contained 48 word pairs (24 A-B targets and 24 $A-B^{\prime}$ items). The A-B targets were randomly assigned to Positions 1-24; the $A-B^{\prime}$ items were randomly assigned to Positions $25-48$. The $s t u d y l$ condition contributed $6 \mathrm{~A}-\mathrm{B}^{\prime}$ items to the list; the study 3 condition contributed $6 \mathrm{~A}-\mathrm{B}^{\prime}$ items that appeared three times each.

The recognition test form included a cue (e.g., childapple, grape, pear, banana, peach) for each of the targets. Each cue contained the stimulus word (child) and five alternatives (the target response plus four novel alternatives), which were arranged in a column in random order. The cues were randomly assigned to order on the test.

There were 24 such items on the recognition test. For any given subject, an $\mathrm{A}-\mathrm{B}^{\prime}$ item (e.g., child-bicycle) preceded the cue for the corresponding A-B target on six occasions, defining the test 1 condition.

All study and test materials were printed in large capital letters on overhead transparencies.

Procedure. The word pairs were shown using an overhead transparency at a $10-\mathrm{sec}$ rate. The subjects' task was to make a sentence for each word pair. Because of the 10-sec time limit, they did not write down their sentences but rated their ability to make a sentence on a 5-point scale. Because some word pairs were presented more than once, the subjects were instructed to make a sentence each time they saw a pair of words.

The study list included $24 \mathrm{~A}-\mathrm{B}$ targets; there were 6 targets for each condition of the experiment (control, study 1 , study 3 , and 
test1). In addition, the study list included $6 \mathrm{~A}-\mathrm{B}^{\prime}$ items for the study 1 condition and another $6 \mathrm{~A}-\mathrm{B}^{\prime}$ items for the study 3 condition. Each $A-B^{\prime}$ item in the study 3 condition was shown three times.

After the study list was shown, the subjects in Experiment $2 B$ left and returned $24 \mathrm{~h}$ later for the recognition test. The subjects in Experiment 2A performed a filler task in order to create a 15min retention interval. They generated a city for each letter of the alphabet (e.g., Atlanta, Baton Rouge, Chicago, etc.).

Memory for the targets was tested using a forced-choice recognition test. For each A-B target, the stimulus word and five alternatives were provided (e.g., child____ apple, grape, pear, banana, peach). The subjects were asked to write down the word that had previously been paired with the stimulus word (A). Each cue was presented for $10 \mathrm{sec}$.

In the test 1 condition, the subjects were shown an $A-B^{\prime}$ item (e.g., child-orange) and then given $15 \mathrm{sec}$ to write down a sentence that included both of the words in the pair. Zero, one, two, or three items intervened between generation of the sentence and testing for memory of the A-B target. It was necessary to vary the lag between sentence generation to the test in order to measure any disruption caused by switching between the tasks. Any disruption would be greatest for an item that was tested immediately after generation of a sentence $(0 \mathrm{lag})$. The conditions were equated for any disruption by testing the targets in each condition at lags of 0 , 1,2 , and 3 equally often. ${ }^{3}$

\section{Results}

The percentage of correct choices in the recognition test is shown for each condition in Table 2. Each percentage is based on 504 observations. In both experiments, performance was equally high in the control and studyl conditions and lower in the test 1 condition.

We made four preplanned pairwise comparisons and constructed a confidence interval for each effect. The familywise error rate was held at .05 by using an $\alpha=$ .0375 for each comparison and a critical $t=2.11$. The confidence intervals are expressed as differences in the percentage of correct responses.

The confidence intervals for each interference effect are shown in Table 1. Experiments $2 \mathrm{~A}$ and $2 \mathrm{~B}$ showed similar interference effects. In both experiments, performance was higher in the control condition than in the test 1 condition. However, performance in the control and study 1 conditions was roughly equivalent.

The extent to which $A-B^{\prime}$ interfered depended on when it was shown. A larger interference effect was found if $A-B^{\prime}$ was shown during the test (control minus test 1 ) than if $A-B^{\prime}$ was shown at study (control minus study 1 ). The magnitude of the interference effect changed by $5.8 \% \pm$ $3.9 \%$ in Experiment $2 \mathrm{~A}$ and by $9.1 \% \pm 5.4 \%$ in Experiment 2B.

\section{Discussion}

The pattern of interference effects found with the word pairs (Experiment 2) was opposite that found for the nature pictures (Experiment 1). The dissociation indicates that the retrieval processes producing the effects found with word pairs were different from those found with the nature pictures.

While the pattern of interference found with the nature pictures suggests a discrimination process, the pattern found with the word pairs does not. According to a discrimination process, performance should be higher if two traces can be discriminated on the basis of their temporal/contextual features (test1) than if they cannot be (study 1 ). The nature pictures showed the predicted pattern; the word pairs showed the opposite pattern.

In the word-pair experiment, an $\mathrm{A}-\mathrm{B}^{\prime}$ item interfered more if it was shown at test rather than at study. This result was found even in Experiment 2B, which was designed to maximize discrimination problems in the study 1 condition. If the traces for $A-B$ and $A-B^{\prime}$ are both $24 \mathrm{~h}$ old, the subject would not be able to use temporal/contextual cues to discriminate between them. Yet, no interference effect was found in the study 1 condition. Instead, A-B' interfered if it was temporally/contextually distinct from $\mathrm{A}-\mathrm{B}$ (test1).

A process other than discrimination must account for the interference effects found with the word pairs. A blocking process seems to be a good candidate, because it can explain why a single $A-B^{\prime}$ item interfered more if it was shown at test rather than at study. The more recent the $A-B^{\prime}$ item, the greater its strength and the more it hinders recognition of the target.

Although it is not critical for our purposes, a blocking process can also explain why $A-B^{\prime}$ interfered more if it was studied three times instead of one time (Experiment $2 A$ ). Showing $A-B^{\prime}$ three times would increase its strength and its chances of blocking the target. At the 24$\mathrm{h}$ retention interval, an $\mathrm{A}-\mathrm{B}^{\prime}$ item studied three times would not interfere, since it would no longer be recent and no longer be primed. Thus, $\mathrm{A}-\mathrm{B}^{\prime}$ items studied a day earlier would not be strong enough to block the target.

\section{EXPERIMENT 3}

Experiment 3 provided converging evidence for the role of a blocking process in recognizing word pairs. According to proponents of blocking processes, a strong trace is sampled at the expense of a weaker trace that is

Table 2

Percentage of A-B Targets Recognized and Confidence Intervals for Interference Effects

\begin{tabular}{cccccccccc}
\hline & & Retention & \multicolumn{5}{c}{ Condition } \\
\cline { 3 - 8 } Design & Experiment & Interval & Control & \multicolumn{2}{c}{ Study1 } & \multicolumn{2}{c}{ Study3 } & Test1 \\
\hline A-B, A-B' & 2A & $15 \mathrm{~min}$ & 94.0 & 91.9 & $( \pm 2.7)$ & 90.1 & $( \pm 3.1)^{*}$ & 86.1 & $( \pm 3.7)^{*}$ \\
& $2 \mathrm{~B}$ & $24 \mathrm{~h}$ & 79.4 & 80.5 & $( \pm 4.6)$ & 78.8 & $( \pm 3.9)$ & 71.4 & $( \pm 5.0)^{*}$ \\
$\mathrm{~A}-\mathrm{B}, \mathrm{A}-\mathrm{C}$ & $\mathbf{3}$ & $15 \mathrm{~min}$ & 93.7 & 94.2 & $( \pm 2.6)$ & 91.9 & $( \pm 3.0)$ & 88.7 & $( \pm 3.3)^{*}$ \\
\hline
\end{tabular}

Note-Standard deviations were calculated for each percentage. They ranged from $12 \%$ to $18 \%$ in Experiment $2 \mathrm{~A}$, from $21 \%$ to $23 \%$ in Experiment $2 \mathrm{~B}$, and from $15 \%$ to $19 \%$ in Experiment 3. Each number in parentheses indicates a confidence interval for an interference effect. *Performance was significantly lower than in the control condition. 
associated with the same retrieval cue (Roediger, 1973; Rundus, 1973). For example, the cue $A$ is common to both $\mathrm{A}-\mathrm{B}$ and $\mathrm{A}-\mathrm{B}^{\prime}$. In this example, there is a preexperimental association between $B$ and $B^{\prime}$, but a preexperimental association is not necessary for a blocking process to occur. A blocking process should also occur in an A-B, A-C design (e.g., child-apple, child-bicycle). Because the cue $\mathrm{A}$ is common to $\mathrm{A}-\mathrm{B}$ and $\mathrm{A}-\mathrm{C}, \mathrm{A}-\mathrm{C}$ may be sampled at the expense of $A-B$. This prediction was tested in Experiment 3 using unrelated words on the test (child: apple, inspector, girl, fever, marbles) and a 15 -min retention interval.

\section{Method}

The design and procedures used in Experiment 3 were identical to those used in Experiment $2 \mathrm{~A}$; only the type of materials changed. In Experiment 3, A-B and A-C items were used instead of $A-B$ and $A-B^{\prime}$ items, and unrelated distractors were the alternatives on the forced-choice recognition test.

Subjects and Design. Another 84 undergraduates participated as subjects in each of the conditions in Experiment 3. The conditions are defined by when the $\mathrm{A}-\mathrm{C}$ item was presented: once at study (study 1), three times at study (study3), once on the test (test1), or not at all (control). Across subjects, each target appeared in each condition equally often.

Materials and Procedure. The targets were 24 pairs of words that were obtained from Graf and Schacter (1987). The stimulus and response words had a low preexperimental association (e.g., child-apple).

Each stimulus term was then paired with another five words. The words came from a pool of 120 unrelated words and were paired with stimulus terms (e.g., child) by random assignment. The process produced five pairs that shared the same stimulus term (e.g., child-bicycle, child-marbles, child-inspector, child-girl, child-fever). One pair was chosen at random to be the A-C item (e.g., child-bicycle); the remaining pairs served as foils on the recognition test. The study lists and tests were constructed in a manner analogous to those of Experiment 2A; the procedure was identical to that of Experiment 2A.

\section{Results}

The percentage of correct responses for each condition in the recognition test is shown in Table 2. Each percentage is based on 504 observations ( 84 subjects responding to 6 items each).

The statistical comparisons were analogous to those in Experiment 2A. ${ }^{4}$ We measured interference by comparing recognition of $\mathrm{A}-\mathrm{B}$ targets in the control condition to each condition in which an A-C item was shown. An A-C item interfered if it was shown on the test (test1) but not if it was shown in the study phase (study1). Confidence intervals for the interference effects are reported for each interference effect in Table 2.

The size of the interference effect was larger if $\mathrm{A}-\mathrm{C}$ was shown in the test phase (control minus test1) rather than in the study phase (control minus study 1 ). The size of the interference effect changed by $5.5 \% \pm 3.5 \%$.

\section{Discussion}

The same pattern of interference effects occurred in Experiments $2 \mathrm{~A}$ and 3 . In both experiments, a competi- tor (either A-B' or A-C) interfered if it was shown on the test, but not if it was shown at study. This pattern of interference effects is best explained by a blocking process in which the retrieval cue samples a recently presented and strong competitor at the expense of the target (A-B).

A discrimination process cannot explain why an item that is dissimilar to the target $(\mathrm{A}-\mathrm{C})$ interferes with recognizing the target. Nor can a discrimination process explain why A-C interferes more if it is temporally and contextually discriminable from the target.

The interference effect that arises from presenting $A-B^{\prime}$ during the test can be compared with part-set cuing effects. As in our study, Todres and Watkins (1981) presented instances (e.g., apple) from categories (e.g., fruits) in a random order and later tested these items using a modified recognition test (e.g., Did you see apple or grape?). Recognition of a target (e.g., apple) decreased by $3 \%$ if other category instances were shown during the test phase. ${ }^{5}$ The interference has sometimes been attributed to lateral inhibition between semantically related items like apple and orange (see Neely, Schmidt, \& Roediger, 1983, for a review). However, lateral inhibition cannot explain why recognition of child-apple decreases if child-bicycle is shown on the test. A blocking process provides a better explanation for the interference that we found in Experiment 3.

While the present experiments suggest that a blocking process can play a role in recognition, it does not play a role in all circumstances. In contrast to the current findings, the typical misinformation study finds no interference in a modified recognition test (see Belli et al., 1992, for a review). In these studies, target items (e.g., hammer) are embedded in slides and are later tested (e.g., Did you see a hammer or a wrench?). In the interim, a story is presented that mislabels some of the items (e.g., screwdriver). Recognition is not affected by the misinformation, perhaps because it was shown at study and does not promote a blocking process. In the present studies, an item interfered only if it was shown in the test phase of the experiment.

While Experiments 2A and 3 suggest that a blocking process plays a role in recognition, an experiment by Chandler and Gargano (1995) suggests that another retrieval process affects cued recall for these materials (e.g., child-app___). In a study analogous to Experiments $2 \mathrm{~A}$ and 3 , Chandler and Gargano tested memory for A-B pairs (e.g., child-apple) using a cued recall test (e.g., child-app__ ). Some test items were preceded by an A-B' item (e.g., child-cookies), an A-C item (e.g., child-bicycle), or nothing (control). Compared with the control, recall increased if $A-B^{\prime}$ was shown but decreased if $\mathrm{A}-\mathrm{C}$ was shown.

Chandler and Gargano's (1995) findings can best be explained by considering the match between the retrieval cue and the trace. According to a process discussed by Martin (1972), which we call "cue-change," an A-B' or $\mathrm{A}-\mathrm{C}$ item primes certain features. If these features remain primed during the test, then they become part of 
the functional retrieval cue (child-app___). Recall increases if the functional retrieval cue reemphasizes features that match the target $\left(\mathrm{A}-\mathrm{B}, \mathrm{A}-\mathrm{B}^{\prime}\right)$ and recall decreases if the retrieval cue emphasizes features that do not match the target $(\mathrm{A}-\mathrm{B}, \mathrm{A}-\mathrm{C})$.

Cue change is not a factor in our recognition test, because the full A-B pair (child-apple) is shown on the test. The cue's meaning is constrained by the contextual words, which are the same at study as at test. Because this cue matches the trace for the target, cue change is not a factor, and we were able to observe a blocking process. The absence of cue change in the recognition test and the presence of a blocking process can explain why presenting $\mathrm{A}-\mathrm{B}^{\prime}$ decreases (rather than increases) recognition accuracy.

\section{GENERAL DISCUSSION}

Past research has acknowledged that accessing a target can be problematic in recognition tests if the retrieval cue does not match the memory trace (see Tulving, 1983, Chap. 11, for a review). In our experiments, the role of encoding specificity was minimized so that we could examine other retrieval processes in recognition. In each condition of our experiments, the context and target words were shown on the test (e.g., child-apple) so that the meaning emphasized by the retrieval cue matched the trace.

Our evidence suggests that two retrieval processes, a blocking process and a discrimination process, can make retrieval problematic in forced-choice recognition tests. Both kinds of retrieval problems arise only if the retrieval cue matches more than one memory trace. The type of materials determines which retrieval process is important in the forced-choice recognition test. While a blocking process influences recognition of familiar word-pair stimuli (Experiments 2 and 3), a discrimination process influences recognition of unfamiliar nature pictures (Experiment 1).

\section{A Blocking Process}

The interference effects found with the A-B word pairs (e.g., child-apple) are best explained by a blocking process. Larger interference effects occurred if the competing item had been shown recently. The effect is consistent with a blocking process that assumes that recent items are stronger and therefore more likely to be sampled at the expense of the target. Consistent with a blocking process, an interference effect occurred regardless of whether the target and competing items were semantically similar $\left(\mathrm{A}-\mathrm{B}, \mathrm{A}-\mathrm{B}^{\prime}\right)$ or semantically dissimilar (A-B, A-C).

On the other hand, a blocking process did not play a role in recognizing the nature pictures (e.g., Did you see Flower $A$ or Flower $A^{\prime \prime}$ ?). In Experiment 1 , the competitor (Flower $A^{\prime}$ ) interfered more if it was shown at study rather than at test. Moreover, there was no interference if
Flower $\mathrm{A}^{\prime}$ was shown only on the test, which leaves no interference to be explained by a blocking process.

Our results suggest two conclusions with respect to a blocking process. Although it was originally proposed to explain interference effects in recall (e.g., Rundus, 1973), a blocking process can account for some interference effects in a forced-choice recognition test. Furthermore, a blocking process may occur for highly familiar codified stimuli (e.g., word pairs) but may not play a role in the recognition of unfamiliar uncodified stimuli (e.g., nature pictures). It is not clear why a blocking process would be important for the recognition of some stimuli and not of others.

Current discussions of a blocking process do not contain a mechanism that can account for differences across materials. However, Jacoby (1991, p. 537) speculated that some interference effects could result from the automatic influence of primed competitors. If so, then familiar words, which show large priming effects, should interfere with recognizing the target. Unfamiliar scenes should show little priming, and should not interfere with recognizing the target. Another possibility is that competitors interfere if they are rehearsed, and familiar materials are more likely to have been rehearsed than are unfamiliar materials.

\section{A Discrimination Process}

A discrimination process provides the best explanation of why Flower $A^{\prime}$ interfered more if it was shown at study rather than at test (Experiment 1). Some modern theories assume that features from two activated traces can recombine during a test (see, e.g., Metcalfe, 1990, and Reinitz et al., 1992). Performance on the forcedchoice recognition test suffers because the merged information does not match any of the test alternatives. By itself, the idea that features can recombine cannot explain our findings. However, the finding can be explained if the theories assume that temporal and contextual cues help to determine which features occurred together as part of the same event. It is easier to discriminate between the Flower $A$ and Flower $A^{\prime}$ features if they had occurred in different contexts (Flower $A$ at study and Flower $\mathrm{A}^{\prime}$ at test) than if they had occurred in the same context (Flower A and Flower $\mathrm{A}^{\prime}$ at study).

The idea that the subject must discriminate between responses (e.g., Postman, 1963, p. 42) or traces (e.g., Underwood, 1969, p. 569) has been around for many years. The current results suggest that the concept of a discrimination process is still useful. More importantly, the findings prompt us to ask about the nature of the discrimination process. How does a person know that certain features occurred as part of an event? And, why would a discrimination process be more important for recognizing nature pictures than word pairs?

The studies differed in many respects, any of which might account for the dissociation. The nature pictures are not presented as paired associates, although they can 
be thought of as paired associates with the category flower associated with two instances, Flower $\mathrm{A}$ and Flower $A^{\prime}$. In addition, the nature pictures are less familiar than the words, they are more perceptual than conceptual, and they do not lend themselves to verbal description or to rehearsal. At this point, we do not know which of these differences are critical. However, we will entertain some possibilities next.

One explanation for the discrepancy in results is that a discrimination process is important for recognizing both nature pictures and word pairs. However, only the nature pictures were encoded with respect to temporal and contextual features. Thus, only the nature pictures showed evidence for a discrimination process based on temporal and contextual features. It has been suggested that environmental context is not encoded for familiar stimuli, such as familiar words (Dalton, 1993). Also, the pairs of words ( fruit-apple) may have focused attention on a semantic association rather than on the environmental context.

Because semantic features of the word pairs were encoded, there should have been evidence for a discrimination process based on semantic features. However, a semantically similar competitor (fruit-orange) did not interfere with recognizing the target (fruit-apple) if both were shown in the study phase. A competitor shown during the test interfered, but did so regardless of whether it was semantically similar to the target $\left(A-B^{\prime}\right)$ or not $(\mathrm{A}-\mathrm{C})$.

The best description of the results is that a discrimination process is important for recognizing nature pictures but not for recognizing words. To explain why this might happen, we offer an account based on differences in the predictability of the target's features. Having an interrelated, predictable set of features could affect both the type of representation and retrieval.

Because a familiar word has a set of predictably interrelated features, these features may be stored and remembered as one unit. In addition, the retrieval cue fruit-apple may activate knowledge of apple, which then cues features that are relevant to it. Because features from traces for items such as apple and orange cluster as distinct units in a retrieval buffer, their features do not recombine. The idea is similar to Metcalfe's (1990) distinction between "coherent" and "noncoherent" blends. Although features of apple and orange are activated at retrieval, they remain distinct within the retrieval buffer. Past knowledge dictates which features constitute the apple versus the orange (coherent blends), thereby preventing improbable recombinations (incoherent blends).

Because prior knowledge can differentiate between familiar words, temporal and contextual features did not play a role in Experiments 2 and 3 . In contrast, the nature pictures have an unfamiliar collection of features. No prior knowledge exists to determine which features belong in a given picture. With such materials, the temporal context may be used to tell which features co-occurred as Flower $\mathrm{A}$ and which features co-occurred as Flower
$\mathrm{A}^{\prime}$. The discrimination process is successful only if these traces are temporally distinct.

According to our view, discrimination based on temporal and contextual features is important for recognizing some verbalizable stimuli as well. The critical variable is whether previous experience predicts a set of interrelated features for the target. An expert apple consumer would be able to discriminate between traces for a gala and a jonagold, because the expert's knowledge constrains which features comprise a gala apple as opposed to a jonagold apple. In contrast, a novice would find it difficult to determine which features occurred together as the gala apple, unless the traces differed in temporal/contextual features.

If our view is correct, then two factors must be added to models such as Metcalfe's (1990). Like Metcalfe, we claim that activating traces simultaneously can result in recombinations of features. However, we specify two conditions that constrain this recombination of features. First, we suggest that features will not recombine if past knowledge dictates that a set of interrelated features should occur together. Second, if past knowledge does not specify which features should occur together, then a collection of features that are linked to temporal and contextual features is encoded. If the temporal/contextual features are unique to an event, they can be used to determine which features co-occurred. This kind of discrimination process is not mentioned by either Metcalfe or Reinitz et al. (1992; Reinitz et al., 1994), but it could easily be added to their models.

Adding this discrimination process to Metcalfe's (1990) model would also correct its tendency to form too many composite traces. In Metcalfe's model, the trace for Flower $A$ is activated while studying Flower $A^{\prime}$. Instead of forming a separate trace for Flower $A^{\prime}$, a composite trace is formed that contains features of both Flower $A$ and Flower $A^{\prime}$. Because there is no separate trace for Flower $A^{\prime}$, memory for this item should be poor compared to a control condition that studies only Flower $A^{\prime}$. Interference effects should be smaller in a retroactive design, because there is a separate trace for the target (Flower A). Contrary to these predictions, Chandler (1991, Experiment 4) found no proactive interference using a 15 -min retention interval that produced reliable amounts of retroactive interference.

What would happen if a discrimination process were added to the model? A composite trace would not be formed, because temporal/contextual features discriminate between the old trace (Flower A) and the current information (Flower $\mathrm{A}^{\prime}$ ). Thus, we would expect little proactive interference.

The revised model would predict similar amounts of proactive and retroactive interference, which also does not match the results. But the findings make sense if it is assumed that recent events (Flower $A^{\prime}$ ) are accessed more rapidly than distant events. In the proactive design, the recent correct information $\left(A^{\prime}\right)$ is activated rapidly and supports an accurate decision. In the retroactive de- 
sign, the recent competitor $\left(A^{\prime}\right)$ is activated before the target (A) and their features recombine. If temporal/contextual features cannot determine which features cooccurred, then interference effects are observed. The pattern of errors in source judgments is also consistent with this explanation. Source judgments should be more accurate if the target alone is activated than if the competitor is also activated. We examined source judgments for trials in which subjects chose the correct picture. In the retroactive design, source judgments were more accurate for unique targets $(75 \%)$ than they were if a competitor was shown $(51 \%)$, suggesting that the competitor was activated by the test cues. In the proactive design, source judgments were as accurate for unique targets $(68 \%)$ as they were for targets preceded by a competitor $(67 \%)$, which suggests that the less recent competitors were not activated by the test cues (Chandler \& Fisher, 1996, pp. 511-512).

Finally, we would like to speculate that a discrimination process happens for conceptual features as well as for perceptual features. Studies have shown that people sometimes remember meaningful objects from two events as having occurred simultaneously (see Johnson, Hashtroudi, \& Lindsay, 1993, for a review). Recombination errors and interference tend to occur when the particular items that constitute an event cannot be predicted. Suppose that you saw a painting that contained dancing peasants and a bowl of fruit, and then see a painting with peasants lolling in the grass and drinking from a wine flask. Later, you remember dancing peasants drinking from a wine flask. Items from the painting and the narrative recombine because (1) both events are cued, and (2) the particular combination of items in either event is arbitrary.

Saying that items are recombined or misattributed to the wrong context does not provide a complete understanding of these errors. A discrimination process is implicated in that the errors occur more often if the events are more similar. A study by Carris, Zaragoza, and Lane (1992) found more errors if the events were similar in sensory characteristics than if they were not. Carris et al. presented slides that were followed by a narrative. Subjects who were asked to imagine the items in the narrative, rather than just reading it, were more likely to remember seeing these items. It may be difficult to discriminate between events if they share sensory characteristics.

\section{Are Retrieval Processes Involved in Recall and Recognition Different?}

A final question of interest is whether or not different retrieval processes are involved in recall and recognition. As we stated in our introduction, all of the major retrieval processes (encoding specificity theory, a feature recombination process, and blocking) were originally proposed to account for effects found in recall. Yet the evidence suggests that all of these processes affect performance in recognition tests.

Thus, there may be less of a difference between recall and recognition than was once thought. Instead, the im- portance of various retrieval processes depends on the type of representation and the retrieval cues. If the retrieval cue can be interpreted in a way that does not match the trace, then evidence can be found for the importance of encoding specificity, regardless of whether the experimenter uses a recall test or a recognition test (e.g., Light \& Carter-Sobell, 1970; Thomson, 1972; Tulving \& Thomson, 1971). Recall of targets (e.g., art-girl) is higher if a weak associate (art) is reinstated than if a strong associate (child) is used as a cue (e.g., Thomson \& Tulving, 1970, Experiment 3). Likewise, recognition of girl is more accurate if the context word is reinstated (e.g., art-girl) than if a new word is used (e.g., adultgirl) (Tulving \& Thomson, 1971).

If the retrieval cue matches the trace for the target and for a competitor, then evidence for other retrieval processes can be found. Although a blocking process was originally proposed to account for interference effects in recall (e.g., Rundus, 1973), our results suggest that a blocking process can occur in recognition (Experiments 2 and 3 ). However, a blocking process was implicated only for the word pairs and only if the competing item was shown during the test. Furthermore, a blocking process may happen only for codified stimuli that are easily rehearsed.

Whether or not a blocking process is involved in recall is unclear. A blocking process has been ruled out as causing some interference effects (see Anderson, Bjork, \& Bjork, 1994, for examples). However, those studies did not include conditions that were most likely to produce a blocking effect. Future studies may find evidence for a blocking process if other retrieval problems are minimized and if the competitors are presented during the test.

Evidence for a recombination of features has been found in both recall and recognition tests for uncodified stimuli. For example, Reinitz et al. (1992, Experiment 2) asked people to study sentences of the form The $X$ saw the $Y$, and asked them to recall the sentences $15 \mathrm{~min}$ later. The most frequent errors in recall were conjunction errors (recalling the $\mathrm{X}$ from one sentence and the $\mathrm{Y}$ from another sentence). In addition, Reinitz et al. (1992) reported that people often recognized conjunction stimuli that recombined features from two studied items. The effects were found in recognizing nonsense words (Experiment 1) and human faces (Experiments 5 and 6).

If features from two activated traces can recombine, the next question is how people determine which features occurred together as an event. Our Experiment 1 shows evidence for a discrimination process in recognizing nature pictures. When features from two traces are activated, temporal and contextual cues can sometimes be used to determine which features co-occurred. If Flower $\mathrm{A}$ and Flower $A^{\prime}$ have different temporal and contextual features, for example, then interference is averted in a recognition test (Experiment 1 ). It is not known whether discrimination problems occur in recall, but it seems likely given that Reinitz et al. (1992) found conjunction errors in recall of uncodified stimuli.

The parallel effects documented here suggest that three retrieval processes originally proposed for recall (en- 
coding specificity, blocking, and discrimination) are important for recognition. The test per se does not matter. Instead, the type of representation and the retrieval cues determine the importance of particular retrieval processes.

It is likely that additional retrieval processes will be discovered for recognition. Researchers have found dissociations between fast and slow judgments and between unintentional and intentional processes, to name a couple (see Jacoby, 1991, for a review). At the present time, it is not clear whether these dissociations reflect differences in retrieval processes or in types of representations, or what retrieval processes might exist. But progress will be made as we specify the type of representations and the specific retrieval processes that underlie these judgments.

\section{REFERENCES}

ANDERSON, M. C., \& BJorK, R. A. (1994). Mechanisms of inhibition in long-term memory: A new taxonomy. In D. Dagenbach \& T. H. Carr (Eds.), Inhibitory processes in attention, memory, and language (pp. 265-325). San Diego: Academic Press.

ANDerson, M. C., BJork, R. A., \& BJork, E. L. (1994). Remembering can cause forgetting: Retrieval dynamics in long-term memory. Journal of Experimental Psychology: Learning, Memory, \& Cognition, 20, 1063-1087.

BatTig, W. F., \& Montague, W. E. (1969). Category norms for verbal items in 56 categories: A replication and extension of the Connecticut norms. Journal of Experimental Psychology Monographs, $80(3$, Pt. 2$)$.

BeLli, R. F., Windschitl, P. D., McCarthy, T. T., \& WinfRey, S. E. (1992). Detecting memory impairment with a modified test procedure: Manipulating retention interval with centrally presented event items. Journal of Experimental Psychology: Learning, Memory, \& Cognition, 18, 356-367.

BJORK, E. L., \& BJORK, R. A. (1988). On the adaptive aspects of retrieval failure in autobiographical memory. In M. M. Gruneberg, P. E. Morris, \& R. N. Sykes (Eds.), Practical aspects of memory: Current research and issues (Vol. 1, pp. 283-288). Chichester, U.K.: Wiley.

CANN, A., \& Ross, D. (1989). Olfactory stimuli as context cues in human memory. American Journal of Psychology, 102, 91-102.

CARrIS, M., ZARAGOZA, M., \& LANE, S. (1992). The role of visual imagery in source misattribution errors. Paper presented at the annual meeting of the Midwestern Psychological Society, Chicago.

Chandler, C. C. (1989). Specific retroactive interference in modified recognition tests: Evidence for an unknown cause of interference. Journal of Experimental Psychology: Learning, Memory, \& Cognition, 15, 256-265.

Chandler, C. C. (1991). How memory for an event is influenced by related events: Interference in modified recognition tests. Journal of Experimental Psychology: Learning, Memory, \& Cognition, 1, 115-125.

Chandler, C. C. (1993). Accessing related events increases retroactive interference in a matching recognition test. Journal of Experimental Psychology: Learning, Memory, \& Cognition, 19, 967-974.

ChANDler, C. C., \& Fisher, R. P. (1996). Retrieval processes and witness memory. In E. L. Bjork \& R. A. Bjork (Eds.), Handbook of perception and cognition: Memory (Vol. 10, pp. 493-524). San Diego: Academic Press.

Chandler, C. C., \& Gargano, G. (1995). Item-specific interference caused by cue-dependent forgetting. Memory \& Cognition, 23, 701-708.

Cutler, B. L., Penrod, S. D., \& Martens, T. K. (1987). Improving the reliability of eyewitness identification: Putting context into context. Journal of Applied Psychology, 72, 629-637.

DaLton, P. (1993). The role of stimulus familiarity in context-dependent recognition. Memory \& Cognition, 21, 223-234.

Delprato, D. J. (1971). Specific-pair interference on recall and associative-matching retention tests. American Journal of Psychology, 84, 185-193.

Gibling, F., \& Davies, G. (1988). Reinstatement of context following exposure to post-event information. British Journal of Psychology, 79, 129-141.

Graf, P., \& Schacter, D. L. (1987). Selective effects of interference on implicit and explicit memory for new associations. Journal of Experimental Psychology: Learning, Memory, \& Cognition, 11, 501-518.

GrAF, P., \& SchaCTER, D. L. (1989). Unitization and grouping mediate dissociations in memory for new associations. Journal of Experimental Psychology: Learning, Memory, \& Cognition, 15, 930-940.

HoRowitz, L. M., \& PRYTULAK, L. S. (1969). Redintegrative memory. Psychological Review, 84, 519-531.

JACOBY, L. L. (1991). A process dissociation framework: Separating automatic from intentional uses of memory. Journal of Memory \& Language, 30, 513-541.

Johnson, M. K., Hashtroudi, S., \& Lindsay, D. S. (1993). Source monitoring. Psychological Bulletin, 114, 3-28.

KePPEL, G. (1991). Design and analysis: A researcher's handbook. (3rd ed.). Englewood Cliffs, NJ: Prentice Hall.

KRafKa, C., \& Penrod, S. (1985). Reinstatement of context in a field experiment on eyewitness identification. Journal of Personality \& Social Psychology, 49, 58-69.

LABerge, D., \& SAmUELS, S. J. (1974). Toward a theory of automatic information processing in reading. Cognitive Psychology, 6, 293323.

Light, L., \& CARTER-Sobell, L. (1970). Effects of changed semantic context on recognition memory. Journal of Verbal Learning \& Verbal Behavior, 9, 1-11.

LoFTUs, E. F. (1979). Eyewitness testimony. Cambridge, MA: Harvard University Press.

MarTiN, E. (1972). Verbal learning theory and independent retrieval phenomena. Psychological Review, 78, 314-332.

MCCloskey, M., \& ZARAGOZA, M. (1985). Misleading postevent information and memory for events: Arguments and evidence against memory impairment hypotheses. Journal of Experimental Psychology: General, 114, 1-16.

MetCalfe, J. (1990). Composite holograph associative recall model (CHARM) and blended memories in eyewitness testimony. Journal of Experimental Psychology: General, 119, 145-160.

MiLlER, G. A. (1956). The magical number seven, plus or minus two. Psychological Review, 63, 81-97.

NEELY, J. H., SCHMIDT, S. R., \& RoEDIGER, H. L., III (1983). Inhibition from related primes in recognition memory. Journal of Experimental Psychology: Learning, Memory, \& Cognition, 9, 196-211.

Postman, L. (1963). Does interference theory predict too much forgetting? Journal of Verbal Learning \& Verbal Behavior, 2, 40-48.

Reinitz, M. T., Lammers, W. J., \& Cochran, B. P. (1992). Memoryconjunction errors: Miscombination of stored stimulus features can produce illusions of memory. Memory \& Cognition, 20, 1-11.

ReINITZ, M. T., MorriseY, J., \& DEMB, J. (1994). Role of attention in face encoding. Journal of Experimental Psychology: Learning, Memory, \& Cognition, 20, 161-168.

ROEDIGER, H. L., III (1973). Inhibition in recall from cueing with recall targets. Journal of Verbal Learning \& Verbal Behavior, 12, 644-657.

ROEDIGER, H. L., III (1978). Recall as a self-limiting process. Memory \& Cognition, 6, 54-63.

RUNDUS, D. (1973). Negative effects of using list items as recall cues. Journal of Verbal Learning \& Verbal Behavior, 12, 43-50.

Salasoo, A., Shiffrin, R. M., \& Feustel, T. C. (1985). Building permanent memory codes: Codification and repetition effects in word identification. Journal of Experimental Psychology: General, 114, 50-77.

Shapiro, P. N., \& Penrod, S. (1986). Meta-analysis of facial identification studies. Psychological Bulletin, 100, 139-156.

Thomson, D. M. (1972). Context effects in recognition memory. Journal of Verbal Learning \& Verbal Behavior, 11, 497-511.

Thomson, D. M., \& Tulving, E. (1970). Associative encoding and retrieval: Weak and strong cues. Journal of Experimental Psychology, 86, 255-262. 
TODRES, A. K., \& WatKINS, M. J. (1981). A part-set cuing effect in recognition memory. Journal of Experimental Psychology: Human Learning \& Memory, 7, 91-99.

Tulving, E. (1983). Elements of episodic memory. Oxford: Oxford University Press, Clarendon Press.

Tulving, E., \& Bower, G. H. (1974). The logic of memory representations. In G. H. Bower (Ed.), The psychology of learning and motivation (Vol. 8, pp. 265-302). New York: Academic Press.

Tulving, E., \& Thomson, D. M. (1971). Retrieval processes in recognition memory: Effects of associative context. Journal of Experimental Psychology, 87, 116-124.

UNDERWOOD, B. J. (1969). Attributes of memory. Psychological Review, 76, 559-573.

WickENs, D. D. (1970). Encoding categories of words: An empirical approach to meaning. Psychological Review, 77, 1-15.

WinDSCHITL, P. D. (1996). Memory for faces: Evidence of retrievalbased impairment. Journal of Experimental Psychology: Learning, Memory, \& Cognition, 22, 1101-1122.

\section{NOTES}

1. Because we are interested in processes that occur item by item, we eliminated list-general causes of interference by alternating control and experimental items within a list (e.g., Delprato, 1971). Response bias and social demands were eliminated by using a modified forcedchoice test (see Chandler, 1989, 1993, and McCloskey \& Zaragoza, 1985 , for arguments).

2. At the $15-\mathrm{min}$ retention interval, the competing trace is recent enough to be activated by cues that resemble it (Flower $A$ and Flower $\mathrm{A}^{\prime \prime}$ ). After 2 days, the competing trace is no longer activated by these cues and does not interfere.

3. Lag did not significantly affect performance in either Experiment $2 \mathrm{~A}\left[F(2,166)=1.249, M S_{\mathrm{e}}=.194\right]$ or Experiment $2 \mathrm{~B}[F(2,166)=$ $\left.1.377, M S_{\mathrm{e}}=.383\right]$.

4. Lag between generating a sentence and making a forced-choice decision did not significantly affect performance in Experiment 3 $\left[F(2,166)=.597, M S_{\mathrm{e}}=.140\right]$.

5 . The interference is offset if studied items are blocked by category and old items are shown in the test phase. The effect has been attributed to a facilitating effect of reinstating the study context (Neely, Schmidt, \& Roediger, 1983; Todres \& Watkins, 1981).

(Manuscript received July 1, 1996; revision accepted for publication January 6,1997 .) 